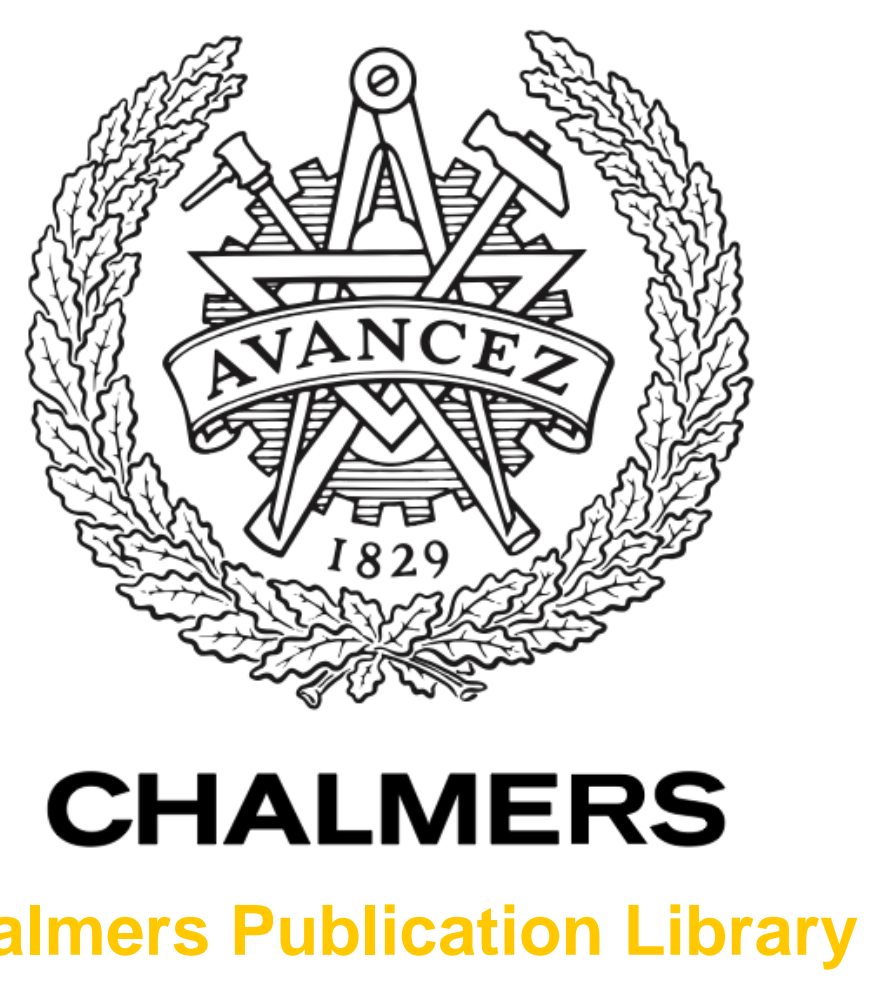

Chalmers Publication Library

The Sanitation Ladder - a Need for a Revamp?

This document has been downloaded from Chalmers Publication Library (CPL). It is the author's version of a work that was accepted for publication in:

Journal of Water Sanitation and Hygiene for Development (ISSN: 2043-9083)

Citation for the published paper:

Kvarnström, E. ; McConville, J. ; Bracken, P. et al. (2011) "The Sanitation Ladder - a Need for a Revamp?". Journal of Water Sanitation and Hygiene for Development, vol. 1(1), pp. 312.

http://dx.doi.org/10.2166/washdev.2011.014

Downloaded from: http://publications.lib.chalmers.se/publication/192466

Notice: Changes introduced as a result of publishing processes such as copy-editing and formatting may not be reflected in this document. For a definitive version of this work, please refer to the published source. Please note that access to the published version might require a subscription. 


\title{
The Sanitation Ladder - a Need for a Revamp?
}

E. Kvarnström*, J. McConville*, P. Bracken**, M. Johansson***, and M. Fogde*

\author{
*: Stockholm Environment Institute, Kräftriket 2B, SE-10691 Stockholm, Sweden (email and telephone of corresponding \\ author: elisabeth.kvarnstrom@ @ei.se, tel: +46-8-6747441, fax: +46-8-6747020, www.sei-international.org) \\ **: AHT GROUP AG, Huyssenallee 66-68, Essen, Germany \\ ***: Ecoloop AB, Mosebacke Torg 4, 11646 Stockholm, Sweden)
}

\begin{abstract}
The sanitation ladder is a useful tool that is being used to monitor progress towards the sanitation target of the MDGs. This tool could be even more useful if it can be refined to be based on the functions of sanitation systems rather than on a hierarchy of predefined sanitation technologies. This paper presents a seven-rung function-based sanitation ladder where the functions can be broadly divided into health functions and environmental functions. The proposed ladder is intended as an inspiration for nations, and the JMP, to move towards a function-based rather than technology-based monitoring of sanitation progress. A functional approach to monitoring of e.g. the sanitation target of the MDGs would require some major shifts in the monitoring methods used but it is argued that such an approach would: (i) actually monitor the public good which is desired from a sanitation system; (ii) stimulate donors, governments, and municipalities to think beyond the provision of certain sanitation technologies; (iii) allow for local solutions to the sanitation problem to be developed; and (iv) spur innovation within the sector.
\end{abstract}

\section{Keywords}

Function-based, Sanitation Technologies, Sustainability, The Sanitation Ladder,

\section{INTRODUCTION}

The importance of sanitation to safe-guard human health is well-known and undisputed. Today, 2.6 billion people have no access to improved sanitation and $17 \%$ of the world's population is practicing 
open defecation (WHO \& UNICEF, 2010). In addition to causing millions of death each year through diarrheal disease, insufficient access to sanitation services is associated with environmental degradation and corresponding poverty levels around the world. Therefore sanitation was included in the Millennium Development Goals (MDGs), adopted by the UN in 2000, which are intended as a guide towards reduction of extreme poverty, with time-bound targets (UN, 2002). One target of MDG 7 focuses on water and sanitation, and challenge the world to halve the proportion of people in 1990 without access to safe drinking water and sanitation by 2015. The Joint Monitoring Program (JMP) of UNICEF and the World Health Organization (WHO) began work in the 1990s with the goals of reporting on the global status of water-supply and sanitation, and to support countries in their efforts to monitor these sectors. Since the establishment of the MDGs, the JMP has naturally assumed the role of monitoring the progress towards the water and sanitation targets. In addition to the JMP strategic objective of compilation, analysis and dissemination of high quality data, another strategic JMP objective is to serve as a platform for the development of indicators, procedures and methods aimed at strengthening monitoring mechanisms to measure sustainable access to water and sanitation (JMP, 2010a).

The JMP has, since 2000, based its reporting on population-based data gathered through large household surveys and national censuses (van der Hoek et al. 2010). Variation in national survey tools has made the comparison of results from different surveys difficult (WHO \& UNICEF, 2006). To address this, WHO and UNICEF have developed a set of core questions on drinking water and sanitation, to be used in household surveys as an attempt to improve on the comparability of data between countries (WHO \& UNICEF, 2006). In the 2000 MDG assessment of progress towards the water and sanitation targets, the JMP distinguished between improved and not improved sanitation facilities (WHO \& UNICEF, 2000). Improved sanitation facilities were defined as being connection to a public sewer, connection to a septic system, pour-flush latrines, simple pit latrines, and ventilated improved pit latrine, whilst not improved facilities were defined as public or shared latrines, open pit latrine and bucket latrines (WHO \& UNICEF, 2000). 
Thus monitoring towards the MDG was performed by considering a set of pre-defined sanitation technologies. However, this approach has been criticized within the sector as it does not deal with issues such as the quality, reliability and sustainability of water and sanitation (Kuznyetsov, 2007). Concerns about using technology-based indicators to monitor the water MDG have been expressed by Sutton (2008). For example, a safe water source exploited using specified technologies does not automatically mean that the water later consumed by the users is safe, which has been shown by several studies (Gundry et al., 2006; Fewtrell et al., 2005). Similarly, sanitation systems that are not used and maintained properly will not provide the intended health and environmental benefits. For the water target Sutton (2008) insinuated that the limited technologies put forward as improved drinking water sources, as monitored by JMP, lead to the development of standards that exclude incremental improvements and progressive risk reduction. In contrast, it was suggested that a broadening of technological options for drinking water and inclusion of progressively improved household access and household-level water treatment may increase the rate of progress towards the water supply MDG (which is access to safe drinking water) without jeopardizing water quality (Sutton, 2008).

Similarly, the classification of sanitation into improved and unimproved technologies raised certain criticism within the sector, due to the exclusion of certain technologies, like composting and urinediverting toilets, from the list of approved technologies. After lobbying from certain groups, composting toilets were added to the list of improved sanitation in 2006 (Werner \& Fischer, 2007). However, incremental expansion of "accepted" technologies as a result of lobbying from different actors does not change the fact that sanitation systems NOT on the pre-defined list of technologies are not counted towards meeting the MDGs.

To allow for a disaggregated analysis of sanitation trends, the JMP refined the indicators in their 2008 report by using their own variation of a tool commonly used in the sector, the sanitation ladder. The sanitation ladder is a well established concept within the water and sanitation sector and is extensively used to illustrate how people can move from simpler sanitation solutions to more advanced ones, by moving up rung by rung on a ladder (Wood et al., 1998, Lenton et al, 2005). It is used in a variety of 
situations, generally as a tool to choose latrine types in community-based water and sanitation projects. Often the first rungs are characterized by a simple latrine, which can be constructed with local material by the user with some locally available assistance. The latrine on the first rung is usually not considered sustainable over a longer period and needs to be replaced when the pit is full. For the higher rungs the requirement for skilled artisanship, technical equipment and spare parts generally increases and the owner needs to have access to funds to be able pay for the installation and to maintain the more fixed and durable infrastructure.

The JMP's adoption of its own version of the sanitation ladder for monitoring purposes (Table 1) is seen as an improvement on the original country assessments done for JMP monitoring. The use of the ladder provides more detailed information of the technology steps the population takes from open defecation to improved sanitation, including for example the use of shared latrines (JMP, 2010b). Although it is an initial attempt at disaggregated analysis of services provided, the ladder adopted by the JMP is still technology-based and does not address all of the issues raised above.

While it is recognized that there are advantages of the more detailed monitoring achieved by the use of a sanitation ladder by the JMP, it is still argued that the sanitation ladder could be further improved by moving from the currently used technology approach to a function approach for monitoring. JMP is ideally placed for leading a change towards a function approach to monitoring, given JMP's ambition to be in the forefront of development of indicators, procedures and methods aimed at strengthening monitoring mechanisms to measure sustainable access to water and sanitation (JMP, 2010a). JMP could thus inspire countries to adopt a function-based approach to sanitation monitoring. Without individual countries adopting a function-based approach, JMP would of course not be able to aggregate function-based data. Other authors have also suggested that the ladder currently used by JMP should be further developed, including e.g. indicators for how facilities are used and related hygiene practices, especially hand washing after defecation (van der Hoek et al, 2010). By focusing on how different functions can be added as one moves up the ladder the sanitation sector leaves room for new technologies and creativity in adapting services to meet the needs of the local context. A 
monitoring system that only allows predefined technologies will work in the completely opposite way, by hampering innovation and creativity. Moreover, a function approach will allow for the outcomes of a functioning sanitation system to be in the centre of the monitoring instead of the sanitation infrastructure that might or might not be used and/or functioning properly. The aim of this paper is to provide some suggestions on how this may be done.

Table 1: Sanitation ladder used by JMP for monitoring of achievement towards the sanitation target of the MDG (WHO and UNICEF, 2008).

\begin{tabular}{|c|c|}
\hline Rung & Description of what counts towards achievement of rung \\
\hline Improved & $\begin{array}{l}\text { Facilities that ensure hygienic separation of human excreta from human } \\
\text { contact. They include: } \\
\text { - Flush or pour-flush toilet/latrine to: } \\
\text { - piped sewer system } \\
\text { - septic tank } \\
\text { - pit latrine } \\
\text { - Ventilated improved pit (VIP) latrine } \\
\text { - Pit latrine with slab } \\
\text { - Composting toilet. }\end{array}$ \\
\hline Shared & $\begin{array}{l}\text { Sanitation facilities of an otherwise acceptable type shared between two or } \\
\text { more households. Shared facilities include public toilets. }\end{array}$ \\
\hline Unimproved & $\begin{array}{l}\text { Facilities that do not ensure hygienic separation of human excreta from } \\
\text { human contact. Unimproved facilities include pit latrines without a slab or } \\
\text { platform, hanging latrines and bucket latrines. }\end{array}$ \\
\hline Open defecation & $\begin{array}{l}\text { Defecation in fields, forests, bushes, bodies of water or other open spaces, or } \\
\text { disposal of human faeces with solid waste. }\end{array}$ \\
\hline
\end{tabular}




\section{TECHNOLOGY VERSUS FUNCTION IN SANITATION - ILLUSTRATIVE EXAMPLES FROM THE REGULATORY AND POLICY FIELDS}

In order to illustrate the effect of a technology-based versus a function-based approach to sanitation a number of different examples from the field of regulation and policy are presented in this section. A technology-based approach to regulation and policy is quite standard world-wide. Regulations and by-laws are in many cases formulated in a technology prescriptive way. They state the sanitation technologies which are authorized for use within the local/regional/national setting, and in the shortterm such policy is an efficient tool for the regulating and monitoring authorities to guide implementation. The downside of this is that regulations, by-laws and legislation formulated in this way might hamper the development and improvement of technology since technologies not specified in the regulatory framework will consequently not be authorized for use. Of course improvement of existing technologies can still occur if there is a (market) demand for such a refinement, but new, innovative technical solutions or designs will have problems entering the scene. The incentive for sanitation experts to promote innovative technologies is also minimal within a technology-based regulation. However, whether encouraged or not, some innovation will take place nationally or internationally. Technology-prescriptive regulatory frameworks will thus become outdated when innovative sanitation technologies not covered in existing regulation will appear on the international sanitation market or through piloting. For example, dry urine-diversion is a sanitation technology that has been implemented in a pilot form in Kampala, Uganda. The technology offered several advantages, but one serious constraint hampering the up-scaling of the pilot experiences, according to post-project evaluations, was the fact that the technology falls under pit latrines regulations in the Public Health Act, even though both the Kampala City Council and the Ministry of Health consider the systems to be quite different from pit latrines (PEM Consult, 2008). Pit latrines must, according to the Public Health Act in Uganda, be constructed at least 30m from the residential home, which means that most plots in Kampala would be too small for implementing urine diversion toilets, as long as they are classified as pit latrines (PEM Consult, 2008). 
Another problem is that technologies not recognized in the regulatory framework will thus not enter statistics even though they may be both functional and appropriate to the context. This in turn may discourage some governments and authorities, struggling to achieve the MDG, to embrace innovative approaches to sanitation as they officially will not be seen as contributions to improving the sanitation coverage.

In contrast, some governments have moved towards more function-based policy, in an attempt to be more inclusive. For example, the South African White Paper on Sanitation (passed 2001) is based on principle rather than technology, stating that the minimum acceptable basic level of sanitation encompasses:

- appropriate health and hygiene awareness and behavior;

- a system for disposing of human excreta, household wastewater and refuse, which is acceptable and affordable to the users, safe, hygienic and easily accessible and which does not have an unacceptable impact on the environment; and

- a toilet facility for each household.

However, the National Building Regulation in South Africa is not function-based, opening up for the Ministry to prescribe specific technologies, e.g. compulsory connection of buildings to sewers (National Building Standards, 1977). So although one policy may allow for innovation, implementation may still be limited to what can be authorized by another policy.

Other countries have pushed for policy that allows for the Best-Available Technique (BAT) to be implemented, as long as it meets a set of functional requirements. The definition of BAT in the European Union Directive 2008/1/EC concerning integrated pollution prevention and control is "Best Available Techniques means the most effective and advanced stage in the development of activities and their methods of operation..." (EU, 2008 page 4). The interesting feature with BAT is that it is used to move targets on practices instead of having fixed goals or specified technologies. 
One example of legislation that has adopted the BAT concept is the Swedish Environmental Code where a number of general rules of consideration are included. These rules also serve as a basis for decisions by regulatory and licensing authorities (Swedish Ministry of the Environment, 2000). In Sweden on-site sanitation regulation has undergone a remake during the last ten years along these lines. The local environmental authorities, being responsible for on-site sanitation permits, used to give permits only to sand filter/infiltration beds or compact wastewater treatment plants. The guidelines, established in 1987, were technology-prescriptive and basically only allowed the previously mentioned technical solutions for on-site wastewater treatment. This hampered the technical development and made it difficult to apply new technologies in situations where the prescribed ones were not feasible. In 2006, the Environmental Protection Agency published new national guidelines for on-site sanitation, which focused not on sanitation technology per se but the function of the sanitation technology instead. The Swedish EPA thereby guides the local authorities on what kind of expected results from the sanitation system they should pose on the house owner. The national guidelines especially emphasize the need to reduce the phosphorus loads to the recipient water bodies and the importance of nutrients recycling. The new national guidelines describe mandatory functions to fulfill within three different categories: (i) basic functions, (ii) health protection, and (iii) environmental protection. The two last categories are further specified into normal protection level and high protection level, where any of these levels can be applied depending on the local context (see Box 1).

The actual effect of these guidelines is, among other things, that a number of new products based on innovative technologies have entered the on-site sanitation market in Sweden. One example is the implementation of "source-diverting systems" which more common now compared to prior to 2006. Some Swedish municipalities have also actively started to work for implementation of so called "black water systems", where the flush water from extremely low-flushing toilets is collected in tanks and then treated through e.g. wet composting, for further reuse on farmland . Other innovative technologies that are gaining ground on the on-site sanitation market in Sweden are: (i) compact treatment plants for onsite use, where wastewater is treated using e.g. down-sized SBR or activated 
sludge processes,(ii) filters containing highly reactive P-sorbing materials and (iii) urine-diverting toilets as complements to conventional soil infiltration or sand filters. Before 2006 all these technical solutions were less common or even non-existent on the Swedish market whereas now they are gaining market shares. These new technologies are also producing new types of wastewater fractions from the households. This has also spurred technical departments in some municipalities to organize systems for reuse of the collected fractions. This is a development that the "pro-urine-diversion" experts have been trying to evoke for more than 10 years, without a major breakthrough until the change of the regulation became a reality in 2006.

To help the local environmental authorities in their decision-making the Swedish EPA has produced a handbook explaining the regulatory implications on the function approach to on-site sanitation (Swedish EPA, 2008). Moreover, many municipalities and some regional authorities have produced "living documents", where technologies fulfilling the function requirements in their municipality for the different protection levels are listed. In order for these documents to be up-to-date with the sanitation system development they need to be regularly updated.

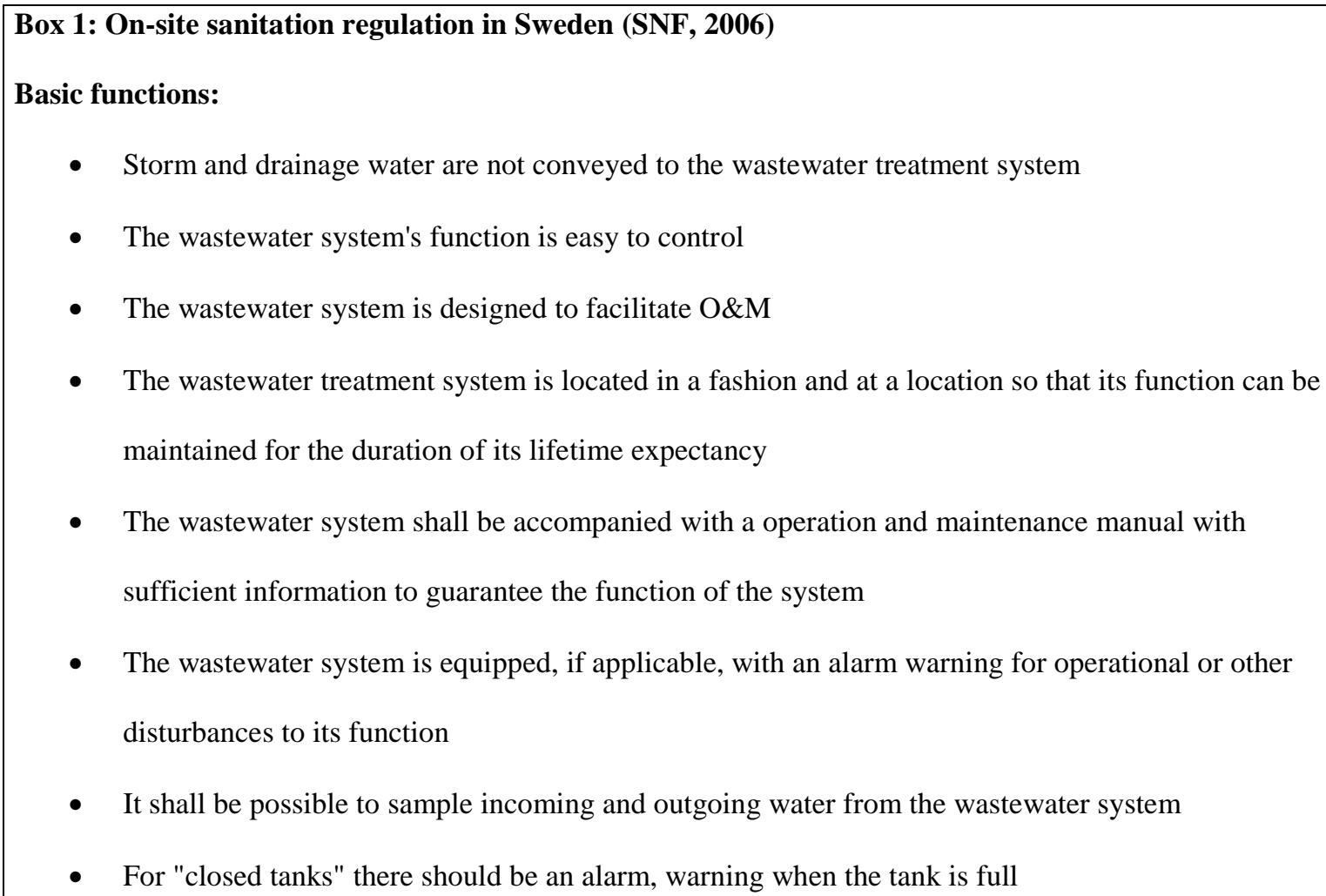

- Storm and drainage water are not conveyed to the wastewater treatment system

- The wastewater system's function is easy to control

- $\quad$ The wastewater system is designed to facilitate O\&M

- The wastewater treatment system is located in a fashion and at a location so that its function can be maintained for the duration of its lifetime expectancy

- The wastewater system shall be accompanied with a operation and maintenance manual with sufficient information to guarantee the function of the system

- The wastewater system is equipped, if applicable, with an alarm warning for operational or other disturbances to its function

- It shall be possible to sample incoming and outgoing water from the wastewater system

- For "closed tanks" there should be an alarm, warning when the tank is full 


\section{Health Protection}

Normal level

- Effluent from the wastewater systems shall not contribute to an important increase in risk for disease transmission or other nuisance (e.g. smell), where people are exposed through contamination of drinking water, groundwater or bathing water.

- In-situ handling of the wastewater fractions from the system can be achieved in a hygienically acceptable way

High level

Further protection measures are taken, when there is an extra need to make the outlet of the system more difficult to access, increase the robustness of the system, and/or add more treatment steps to (i) further improve the treatment, (ii) increase the retention time, (iii) to level out flows, or to (iv) receive overflow from the system.

\section{Environmental Protection}

Normal level

- Use of water-saving faucets and other devices

- Use of phosphate-free detergents and household chemicals

- The system can be expected to achieve at least $90 \%$ reduction of BOD

- $\quad$ The system can be expected to achieve at least $70 \%$ reduction of $\mathrm{P}$ (tot-P)

- The system facilitates reuse of nutrients from the wastewater fractions or other rest products

\section{High level}

- All of the above, and also

- The system can be expected to achieve at least $90 \%$ reduction of phosphorus (tot-P)

- The system can be expected to achieve at least 50\% reduction of nitrogen (tot-N)

\section{CHANGING THE SANITATION LADDER - RESULTS AND DISCUSSION}


In the same way that technology-prescriptive regulation can hamper development as outlined above, technology prescriptive sanitation ladders used for measuring the achievement towards the MDGs or progress at a country-level could also provide unnecessary inertia in sanitation development. It is therefore suggested that a function-based approach is considered for refinement of the sanitation ladder (Table 2); where the lower rungs address issues of health, while the higher rungs include environmental protection and more integrated approaches to sanitation such as integration with management of greywater, resource reuse and recovery. In developing this function-based ladder an attempt has been made to keep the functions as technology neutral as possible, and also to make them universally applicable. It is important to remember that even systems with sewers and wastewater treatment plants can be classified on this ladder, and that they might not necessarily be at the top.

The presented function-based ladder is purposely made comprehensive, including functions all the way from basic to highly advanced levels. The reason for this is that the proposed ladder should be seen as an attempt to inspire for a function-based approach to sanitation monitoring irrespective of where the country is on its sanitation development path. It is then the responsibility of each country, or the JMP in case of MDG monitoring, to define which rungs are of importance to monitor in their context, and thus adapt their own function-based sanitation ladder, which may include all or only a few of the suggested rungs.

Although it is recognized that sanitation is a community issue and that complete health protection will only come when the entire environment is free from excreta, the proposed ladder focuses mainly on individual systems and how individual systems function to keep the immediate surroundings free from excreta. 
Table 2: Suggested function-based Sanitation Ladder*

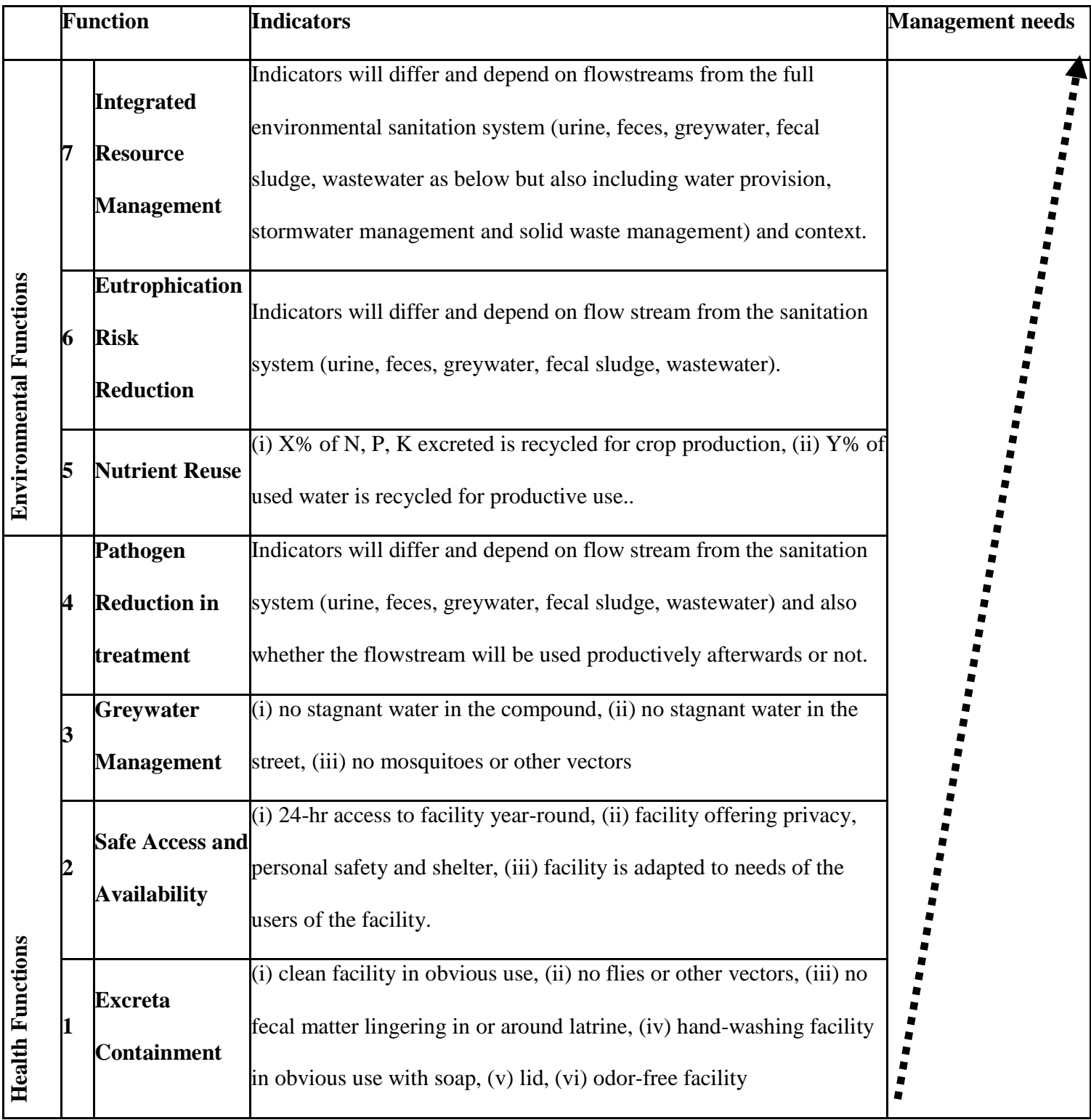

\footnotetext{
* Note that moving up the ladder means that the functions below have also been fulfilled!!
}

The functions on the first rung are focused on stopping the spread of fecal-oral disease through proper excreta containment. This rung recognizes that the use of a public or shared latrine as well as individual latrines, with a functional hand-washing facility, will be able to count towards improved sanitation. The indicators chosen for efficient excreta containment are based on the importance of proper disposal, clean platform, vector and rodent control, as well as, hand washing for health protection (Mara \& Feachem, 1999; Curtis \& Cairncross, 2003). To break the disease chain systems 
aspiring to achieve the first rung should thus (i) be in obvious use and clean, (ii) be free of vectors including flies and rodents, (iii) have no fecal matter lingering in or around the latrine, (iv) provide a hand washing facility, and (v) a lid. In addition, this rung addresses important issues for user satisfaction and acceptance by having aesthetic functions. The pleasantness of the user experience with a sanitation system can be a determinant of whether it is used properly, and thus whether it is providing the necessary benefit or not. Therefore, it is important that the facilities are also (vi) free of odors and have regular cleaning and maintenance to preserve a clean/pleasant experience. In periurban areas, where there is a need for an emptying service to keep the latrine functioning, the proxy of an operational emptying and handling service could be used to assess the overall excreta containment efficiency. It is recognized that the addition of hand-washing on this first rung will make it difficult to attain. However, its position on rung one is motivated, given the importance hand-washing plays for breaking the cycle of sanitation-related diseases.

In addition to assuring the functions on the first rung, the second rung considers the issue of safe access and availability, which means that all users of the specific latrine have safe, reliable access to the sanitation facilities 24-hours a day; including privacy, personal safety, and shelter. The latrine should meet the intended users' needs on the latrine. Hence, the special needs within a specific family or small group of families should be met by that specific latrine, whether it is adaptation to cater for children, women, elderly, or handicapped. Essentially the facility must be very close to or within the individual compound to really count on the second rung. This would be the equivalent of "improved sanitation" in the JMP ladder used today, but the functional formulation suggested here does not exclude any latrine that can provide excreta containment, security, regular access, cleanliness, and hand-washing, which could also be achieved for latrines e.g. shared between a fewer number of families.

The third rung keeps all the functions from the lower steps with the addition of greywater management. This implies that the household has no stagnant water within the compound, or in the street outside the compound. It thus requires proper management of greywater (shower, dish and wash 
water) and a properly maintained individual household latrine, or its equivalent, to be counted on the third rung. This is actually a step above the current JMP sanitation ladder, since it gives attention to greywater and the need for its proper management by users and local authorities to ensure systems to remove or control stagnant water. The indicator on vector control is repeated here, since in this case the vectors the monitoring person should look for are related to effects of stagnant greywater (e.g. mosquitoes), whereas in rung 1 the vectors the monitoring person should look for are related to effects of poorly functioning excreta containment, e.g. flies inside the latrine.

The fourth rung is the first rung that includes functions for the wider environment and population beyond the household. Again, all the functions on the lower steps still apply, and treatment of the excreta is now added to assure pathogen reduction in treatment. Through treatment and pathogen reduction the general population (downstream or otherwise) benefits from removal of excreta from the environment. This rung also paves the way for resource recovery from the sanitation system, by demanding secondary treatment of the human excreta and greywater. Appropriate indicators to use for this step will be dependent on the type of sanitation system in place and the flow-streams (urine, feces, fecal sludge, greywater, wastewater, etc.) generated within the system. Different technologies for the treatment of different sanitation flow-streams are listed in SANDEC (2009). Proxies such as time, temperature, $\mathrm{pH}$, technologies could be used as indicators of achievement of this rung. Guidelines on the safe agricultural use of wastewater, human excreta and greywater have been published by the World Health Organization (WHO 2006), where the use of proxies is also explained.

The fifth rung begins to close-the-loop on resource flows through nutrient reuse. This is attained if the nutrients in the human excreta are reused for crop production or other productive uses, keeping in mind that lower rungs of treatment and pathogen reduction have already been fulfilled. At this step what was once considered "waste" has become a resource for users in addition to all the health benefits generated at the lower rungs of the ladder. This rung also is an efficient mean to address eutrophication reduction, which appears in the next rung, since through reuse much of the potential eutrophication risks can be reduced. Examples of indicators here could be that a percentage of N, P, 
and $\mathrm{K}$ excreted are recycled for crop production and that a percentage of used water is productively reused. To get an understanding of nutrient mass flows, nutrient balances can be made based on number of people in a town, region, country, and on their dietary intake of foodstuff as described in Jönsson and Vinnerås (2004). For monitoring of reuse taking place on household level questions relating to reuse patterns can be incorporated into household surveys. Quantitative monitoring of offsite reuse can include volumes collected, combined with an understanding of the nutrient mass flows. If this is too complicated there is also a possibility to use qualitative indicators for monitoring of offsite reuse. One example of this is to check whether there is a service chain in place for collection and reuse. If there is no such system in place, whether formal or informal, it is reasonable to assume that the off-site reuse is not taking place.

The sixth rung is aimed at protecting the natural environment through the reduction of eutrophication $\underline{\text { risks. }}$ This rung means that there are measures in place to control the nutrients in the effluent of the chosen sanitation system. The choice of sanitation system will determine the effluent flow-streams and thus the appropriate indicators. Quantitative indicators on BOD, N and P content would be reasonable for wastewater and greywater, where appropriate values would depend on the recipient's status. It should be noted that rung six can be achieved without achieving rung five. However, fulfilling rung five is an efficient mean of also tackling eutrophication risks, thus the justification for having nutrient reuse before reducing eutrophication risks in the ladder.

The seventh rung is integrated resource management, which in terms of sanitation means that different streams of waste (e.g. stormwater, wastewater/excreta, greywater, solid waste) are collected and managed together so as to achieve maximum benefits from treatment and reuse (including reuse of water, nutrients, solid waste). When this stage is reached full concern is taken for human health, the environment and the sustainability of the interconnected systems. Indicators would depend on flowstreams and also the local context. 
It is obvious that the costs of the systems will increase while moving up the ladder, as will needs for management and logistical and institutional capacity. It is important to notice how the responsibilities shift from user-related aspects to broader environmental functions as one moves up the ladder. In general, this corresponds to a shift in operation and management (O\&M) needs as well, often with the responsibility moving from household-centered to off-site treatment and management, demanding appropriate institutional set-ups to deal with the shift in responsibility. The first five rungs can be handled on-site if there is enough space available for secondary treatment and reuse and the households are trained in appropriate health and hygiene measures. However, there will be differences in management between rural and urban areas so it is difficult to include stricter management functions in the basic ladder (e.g. a rural composting toilet with household management could end up near the top of the ladder, while a urban centralized sewage system dumping into the ocean is only half-way up). In peri-urban or urban areas it is reasonable to believe that fourth to seventh rung must be handled by a service provider, either by the municipality or a private service provider.

In addition, at the sanitation program level, there is a need to address the drivers, both within institutions and in the population, for moving up the ladder, which will differ considerably depending on context and current rung on the ladder. It is also possible that the sanitation ladder could be used to identify and target "selling-points" for creating a demand to move upwards on the ladder.

It is understood that monitoring progress towards the MDGs will not allow for quantitative monitoring (hence, where treatment performance is quantified by e.g. lab tests, numerical measurements such as effluent concentrations, etc.). However, the three first rungs of the ladder can make do with qualitative monitoring based on observations, which can be achieved through adaptation of existing monitoring procedures. The first three rungs may also be the rungs of most interest from an MDG and JMP perspective, whereas the higher rungs could be of interest for national monitoring/regulation development for countries which are further along in the sanitation development process. Discussions are currently being held for the possible testing of the function-based sanitation ladder in Bolivia, with the aim to further develop the concept in an MDG perspective. 
It is argued that a function-based approach instead of a technology-based approach will be one means to actually harmonize monitoring in different contexts as it is the outcomes of sanitation that are in focus rather than the technology itself. A function-based approach would thus be one way of making the monitoring more reliable and comparable. It is thought that a new set of harmonized questions for household surveys, much in-line with the existing Core Questions for Drinking Water and Sanitation Household Surveys (WHO \& UNICEF, 2006), could be developed for monitoring of progress in relation to a function-based ladder.

One potential problem with this ladder is that partial fulfillment of each rung is possible, so monitoring and scoring of progress up the ladder may have to be done with some partial scoring, e.g. not-met, low-partially fulfilled, high-partial, fully met. Moreover, the functional ladder presented here provides a framework for a potential monitoring system; however it would need to be complimented with detailed indicators and scoring for effective use as a monitoring tool.

\section{CONCLUSIONS}

The sanitation ladder is a useful tool for among other things, monitoring progress towards the MDGs. This tool can be even more useful if it can be refined to use a function approach rather than a technology approach for each rung. This paper has presented a seven step sanitation ladder where the seven steps can be divided into health functions and environmental functions. The first step on the ladder is focused on excreta containment and the last step is comprised of an integrated approach to environmental sanitation. It is are acknowledged that what is presented as a function-based sanitation ladder in this paper is only an outline, and that adoption of a function approach by e.g. the JMP would demand a huge shift in monitoring processes and that the indicators of the rungs to measure MDG achievement would have to be qualitative. Even so, the authors still believe that the function approach would be (i) much more accurate in actually monitoring the achievement on nation-level and of the MDGs and (ii) assessing the public-good that should be the result of the sanitation systems. Moreover, 
it will also force donors, nations and municipalities to think beyond purely sanitation infrastructure provision. This could spur innovation within the sanitation sector and allow for local solutions to the sanitation problem. It is therefore argued that it would be worthwhile to reconsider the monitoring processes both on nation-level and for the MDGs, and ultimately shift the focus from technology to function for the sanitation target in the future.

\section{REFERENCES}

Curtis, V and Cairncross, S. (2003): Effect of washing hands with soap on diarrhoea risk in the community: a systematic review. The Lancet Infectious Diseases, 3, 275-281.

Fewtrell, L., Kaufmann, R., Kay, D. Enanoria, W., Haller, L. Colford, J. 2005 Water, sanitation and hygiene interventions to reduce diarrhea in less developed countries: a systematic review and meta-analysis. Lancet Infect. Dis. 5: 42-52.

Gundry, S., Wright, J., Du Preez, M., Genthe, B., Moyo, S., Mutisi,C., Ndamba, J.,Potgeiter, N. 2006 Contamination of drinking water between source and point-of-use in rural households of South Africa and Zimbabwe: implications for monitoring the Millennium Development Goal for water. Water Practice \& Technology, 1(2).

van der Hoek, W., Evans, B., Bjerre, J., Calopietro, M.J., Konradsen, F. 2010. Measuring progress in sanitation. www.danidadevforum.um.dk/.../MeasuringprogressinsanitationFinaldraft.doc, accessed November 3, 2010.

JMP, 2010a. http://www.wssinfo.org/home/mission.html, accessed November 3, 2010.

JMP, 2010b. http://www.wssinfo.org/definitions/ladders.html , accessed on Sept 13, 2010

Jönsson, H. \& Vinnerås, B. 2004.Adapting the nutrient content of urine and feces in different countries using FAO and Swedish data. In: Ecosan - Closing the loop. Proceedings of the $2^{\text {nd }}$ International Symposium on Ecological Sanitation, incorporating the $1^{\text {st }}$ IWA specialist group conference on sustainable sanitation, April 7-11, 2003, Lübeck, Germany. pp 623-626.

Kuznyetsov, V. 2007 Millennium Development Goals - Problems of Turning Commitment into Reality. Stockholm International Water Institute: Abstract Volume World Water Week, Stockholm, August 12-18, 2007.

Lenton, R., Wright, A., and Lewis, K. 2005. Health, dignity and development: what will it take? Earthscan 8-12 Camden High Street, London, NW1 0JH, UK.

Mara, D.D. \& Feachem, R.G.A. 1999. Water- and Excreta-Related Diseases: Unitary Environmental Classification. Journal of Environmental Engineering, 125(4), 334-339.

National Building Regulations and Building Standards South Africa. 1977 To provide for the promotion of uniformity in the law relating to the erection of buildings in the areas of jurisdiction of local authorities; for the prescribing of building standards; and for matters connected therewith. Act-No 103 of 1977. 
Official Journal of the European Union. 2008 DIRECTIVE 2008/1/EC OF THE EUROPEAN PARLIAMENT AND OF THE COUNCIL of 15 January 2008 concerning integrated pollution prevention and control. 8 - 29.

PEM Consult. 2008 Final Evaluation of KCC - Promotion of EcoSan in Kampala, Uganda. Non-published report. SNF 2006:7. Naturvårdsverkets allmänna råd [till 2 och 26 kap. miljöbalken och 12-14 och 19 §§ förordningen (1998:899) om miljöfarlig verksamhet och hälsoskydd] om små avloppsanordningar för hushållsspillvatten. Swedish Environmental Protection Agency. (Title in English: The Swedish EPA general advice (referring to chapters 2 and 26 of the Environmental Code, and paragraphs 12-14 and 19 of the ordinance (1998:899) on hazardous activities and public health) on on-site sanitation systems for treatment of household wastewater)

Sutton, S. 2008 The risks of a technology-based MDG indicator for rural water supply. In Jones, H (ed.) Access to sanitation and safe water: Global partnerships and local actions. Proceedings of the $33^{\text {rd }}$ WEDC International Conference held in Accra, Ghana. WEDC, Loughborough University, UK.

Swedish EPA 2008 Små avloppsanläggningar - Handbok till Allmänna råd. Swedish EPA, 2008:3, $1^{\text {st }}$ edition, Stockholm, Sweden. (Title in English: On-site sanitation systems - A handbook to accompany the EPA general advice) Swedish Ministry of the Environment. 2000 The Swedish Environmental Code. Ds 2000:61. Ministry publications series. United Nations. 2002 Report of the world summit on sustainable development. United Nations, New York. A/CONF.199/20. Werner, C. \& Fischer, J. 2007 Monitoring of Sanitation Millennium Development Goals and Necessary Criteria Improvements. Stockholm International Water Institute: Abstract Volume World Water Week. Stockholm, August 12-18, 2007.

WHO. 2006 Guidelines for the safe use of wastewater, excreta and and greywater. Volume 1-4. Geneva, Switzerland: WHO Press.

WHO \& UNICEF. 2000 Global water supply and sanitation assessment 2000 report. Geneva, Switzerland: WHO Press. WHO \& UNICEF. 2006 Core Questions for Drinking Water and Sanitation Household Surveys. Geneva, Switzerland: WHO Press

WHO \& UNICEF. 2010 Progress on Drinking Water and Sanitation - 2010 Update. Geneva, Switzerland: WHO Press.

Wood, S., Sawyer, R., and Simpson-Herbert, M. 1998. PHAST step-by-step guide: a participatory approach for the control of diarrhoeal disease. Geneva, World Health Organization (unpublished documents WHO/EOS/98.3) 